\title{
Severe theophylline poisoning treated with continuous venovenous hemodialysis in a child
}

\author{
Ayhan Yaman ${ }^{1}$, Tanıl Kendirli¹, Çağlar Ödek ${ }^{1}$, Ebru Azapağasi1, Hatice Erkol², \\ İbrahim Etem Pişkin ${ }^{3}$, Serap Teber-Tıraş ${ }^{4}$, Fatoş Yalçınkaya ${ }^{5}$ \\ ${ }^{1}$ Divisions of Pediatric Intensive Care, ${ }^{4}$ Pediatric Neurology, ${ }^{5}$ Pediatric Nephrology, and ${ }^{2}$ Department of Pediatrics, Ankara \\ University Faculty of Medicine; Ankara, ${ }^{3}$ Department of Pediatrics, Bülent Ecevit University Faculty of Medicine, Zonguldak, \\ Turkey. E-mail: dryamanayhan@yahoo.com.tr \\ Received: 7 August 2015, Revised: 7 January 2016, Accepted: 25 January 2016
}

SUMMARY: Yaman A, Kendirli T, Ödek Ç, Azapağası E, Erkol H, Pişkin İE, TeberTıraş S, Yalçınkaya F. Severe theophylline poisoning treated with continuous venovenous hemodialysis in a child. Turk J Pediatr 2016; 58: 297-300.

Theophylline poisoning generally occurs due to acute high dose intake as well as chronic intake of the medication. Toxicity symptoms can be seen with a plasma concentration of theophylline over $20 \mu \mathrm{g} / \mathrm{ml}$. The consequences of theophylline toxicity include metabolic disturbances (hypokalemia, hyperglycemia, and metabolic acidosis), nausea, vomiting, and in severe cases seizures, cardiac arrhythmias, and death. Theophylline poisoning in children is rarely described in the literature. A 3-year-old girl was referred from another hospital to our pediatric intensive care unit (PICU) due to prolonged refractory status epilepticus and respiratory failure linked with severe theophylline poisoning. The patient was admitted to our PICU 24 hours after the patient took theophylline. The referring center could not measure the serum theophylline level. The patient's first serum theophylline level that was checked at admission was $54 \mu \mathrm{g} / \mathrm{ml}$. We started continuous venovenous hemodialysis (CVVHD) 3 hours after PICU admission and the patient's theophylline level successfully decreased within 9 hours. The patient was discharged at the $40^{\text {th }}$ day of admission from our hospital with severe neurological disability. In conclusion, severe theophylline poisoning may be seen in children. We must consider CVVHD in critically ill children with severe theophylline poisoning.

Key words: theophylline poisoning, seizures, pediatric intensive care unit, continuous venovenous hemodialysis, children.

Theophylline is a commonly used drug in the treatment of acute or chronic lung disease. Despite the considerable potential benefit of theophylline, its narrow therapeutic range and erratic absorption and elimination contribute to the potential for toxicity, which can have high morbidity and mortality ${ }^{1,2}$. The therapeutic steady state serum concentration for theophylline ranges from 10 to $20 \mu \mathrm{g} / \mathrm{ml}$ when it is used in the treatment of asthma. Other indications have lower therapeutic ranges. Consequences of theophylline intoxication include metabolic disturbances (hypokalemia, hyperglycemia, and metabolic acidosis), nausea, vomiting, and in severe cases seizures, cardiac arrhythmias, and death $^{3}$. Theophylline poisoning in children is rarely described in the literature. For this reason, we report here a case of accidental severe theophylline poisoning, discussing clinical and laboratory manifestations, management, effective treatment with continuous venovenous hemodialysis (CVVHD) and evaluation. There have been no previous cases of children treated by this dialysis method for theophylline poisoning.

\section{Case Report}

A 3-year-old-girl was referred from another hospital to our pediatric intensive care unit (PICU) due to prolonged refractory status epilepticus and respiratory failure linked with severe theophylline poisoning. Being previously healthy, 24 hours before the admission the child took her grandmother's sustained release theophylline and indapamide tablets. The family was not sure how much she had taken 
Table I. Evolution of Laboratory Tests

\begin{tabular}{lccc}
\hline Laboratory parameters & $\begin{array}{c}\text { Values at PICU } \\
\text { admission }\end{array}$ & $3^{\text {rd }}$ hour of CVVHD & $9^{\text {th }}$ hour of CVVHD \\
\hline Hemoglobin (g/dl) & 12.6 & - & 10.3 \\
White blood cell (x 109/L) & 29.1 & - & 17.6 \\
Platelets (x109/L) & 320 & - & 243 \\
Glucose ( mg/dl) & 41 & 83 & 117 \\
BUN (mg/dL) & 46 & 18 & 9 \\
Creatinine (mg/dl) & 1.12 & 0.53 & 0.44 \\
Na (mEq/dl) & 138 & 136 & 136 \\
K (mEq/dl) & 4.1 & 4.1 & 5.1 \\
Ca (mg/dl) & 9.1 & 8.6 & 9.3 \\
Uric acid (mg/dl) & 9.8 & 3.5 & 2.3 \\
Total bilirubin (mg/dl) & 1.16 & - & 1.43 \\
ALT (U/L) & 48 & 111 & 132 \\
AST (U/L) & 199 & 430 & 426 \\
Lactate (mmol/L) & 2.6 & - & 1.6 \\
CK-MB (ng/ml) & 239 & - & 304 \\
Troponin I (ng/ml) & 1.91 & - & 0.29 \\
Myoglobin (ng/ml) & 3814 & - & 1024 \\
\hline
\end{tabular}

ALT: Alanine aminotransferase; AST: Aspartate aminotransferase; BUN: Blood urea nitrogen; Ca: Calcium; CK-MB: Creatine kinase MB; CVVHD: Continuous venovenous hemodialysis; K: Potassium; Na: Sodium; PICU: Pediatric intensive care unit.

of each medication. Six hours after taking these medications, the patient started to vomit repeatedly and have seizures. The condition was consistent with generalized tonic-clonic seizures in the whole body and the patient remained in that status for four hours. Midazolam intravenous (IV) push was administered. Phenytoin was given and midazolam infusion was started to bring the seizures under control.

When she was admitted to our PICU, she was intubated. In her physical examination, she was unconscious (receiving midazolam infusion), her body temperature was $39.8{ }^{\circ} \mathrm{C}$ (axillary), heart rate: $200 / \mathrm{min}$, and blood pressure: $65 / 49 \mathrm{mmHg}$ (hypotensive). The patient's mouth mucosa was dry and eyeballs sunken. Also, she suffered from severe dehydration. The patient's neurological examination was not fully assessed due to receiving midazolam infusion. The patient's pediatric risk of mortality III score was 20 and pediatric logistic organ dysfunction score was 22. The patient's blood sugar was $41 \mathrm{mg} / \mathrm{dl}$. Kidney functions were impaired. Laboratory results are shown in Table I. For the patient's hypoglycemia a $10 \%$ dextrose push was given at a dose of $5 \mathrm{ml} / \mathrm{kg}$. Normal saline loading was given to the patient twice at a dose of $20 \mathrm{ml} / \mathrm{kg}$. We gave fluid to the patient as maintenance and for $10 \%$ deficit. The patient was ventilated with synchronized intermittent mandatory ventilation + pressure support mode by mechanical ventilation. Midazolam infusion $(0.2 \mathrm{mg} / \mathrm{kg} /$ hour $)$ was maintained. Later, phenytoin treatment was stopped since it is contraindicated in theophylline poisoning. Control blood sugars returned as $55 \mathrm{mg} / \mathrm{dl}$ and $70 \mathrm{mg} / \mathrm{dl}$. Despite fluid deficit, due to the patient having hypotension, dopamine infusion was started at a dose of $10 \mu \mathrm{g} / \mathrm{kg} / \mathrm{min}$. Due to the patient's high fever, paracetamol IV was administered. Also, hypothermia was applied to the patient with the method of blanket that is laid under the whole body. Two hours after the patient's admission into our PICU, her fever came down and tachycardia regressed. Blood pressure returned to normal.

The first serum theophylline level that was checked at admission was $54 \mu \mathrm{g} / \mathrm{ml}$. We inserted a $7 \mathrm{Fr}, 15 \mathrm{~cm}$ double lumen amecath catheter (Ameco Medical Industries, Ramadan City, Egypt) into the right internal jugular vein. CVVHD was started 3 hours after arrival at the hospital (27 hours after ingestion). CVVHD was administered using a hemofilter HF 20 circuit (Gambro-Prismaflex, lundia AB, Sweden). The extracorporeal circuit was primed with $58 \mathrm{ml}$ of $5 \%$ albumin. Priming was done to the patient with $5 \%$ albumin in order to avoid hypotension. The blood-pump flow rate was $80 \mathrm{ml}$ per minute (6 $\mathrm{ml} / \mathrm{kg}$ per minute). Dialysate fluid rate was 


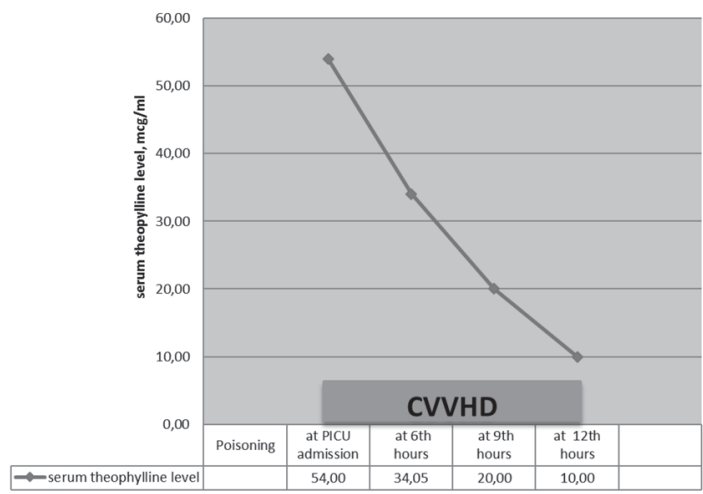

Fig. 1. Patient's serum theophylline levels following the start of CVVHD

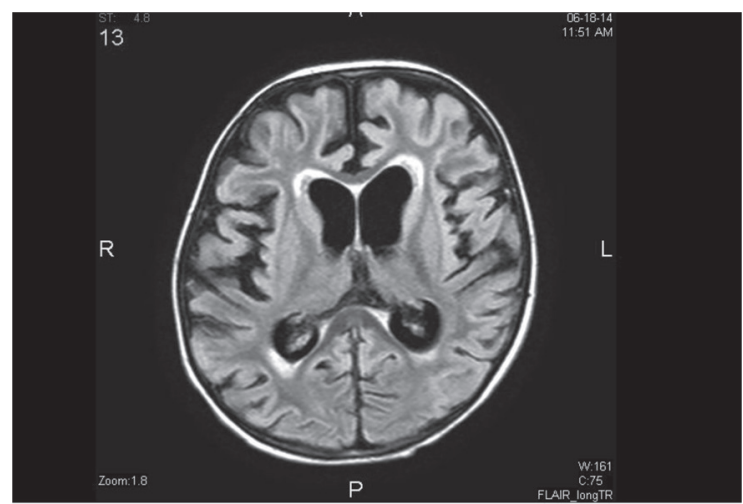

Fig. 2. Extensive cortical atrophy in cerebral hemisphere signal increase in FLAIR examination (hypotension/ hypoperfusion and changes linked with hypoxic influence) and enlargement in ventricular systems due to secondary atrophy.

$200 \mathrm{ml}$ per hour $\left(20 \mathrm{ml} / \mathrm{kg}\right.$ per hour, multiBic ${ }^{\circledR}$; $\mathrm{Na} 140 \mathrm{mmol} / \mathrm{L}$, K $3.0 \mathrm{mmol} / \mathrm{L}$, Ca $1.5 \mathrm{mmol} / \mathrm{L}$, bicarbonate $35 \mathrm{mmol} / \mathrm{L})$. Replacement fluid rate was $543 \mathrm{ml}$ per hour $\left(2,000 \mathrm{ml} / \mathrm{m}^{2} / 1.73\right.$ per hour - her body surface area was $0.47 \mathrm{~m}^{2}$ ). Anticoagulation of the extracorporeal circuit was achieved using heparin. During CVVHD, theophylline levels were measured at 3 hour intervals. The patient's serum theophylline level under CVVHD is shown in Figure 1. CVVHD was terminated 9 hours after initiation when the serum theophylline level was $10 \mu \mathrm{g} / \mathrm{ml}$. There was no complication during CVVHD.

Weaning from mechanical ventilation was planned for the patient on the $4^{\text {th }}$ day of her admission. Midazolam infusion was reduced and stopped, after which the patient had two seizures. As a result, midazolam infusion was re-applied. The patient's seizures continued and the midazolam infusion dose was increased to $0.4 \mathrm{mg} / \mathrm{kg} / \mathrm{hr}$. Phenobarbital loading was administered and maintenance was started.
Cranial tomography revealed brain edema and ischemic changes at admission. Brain edema was treated with hypertonic saline infusion (up to 3 $\mathrm{ml} / \mathrm{kg} / \mathrm{hrs}$ ) and mannitol infusion was started. In the follow-up, seizures were brought under control. Afterwards, brain magnetic resonance imaging also revealed diffuse ischemic changes linked with hypoperfusion (Fig. 2).

The patient was extubated on the $18^{\text {th }}$ day of admission. The patient's eyes were spontaneously open, however there was no cooperation with the environment. She was not able to hold her head and demonstrat involuntary movements. The patient was referred to the pediatric neurology department on the $25^{\text {th }}$ day with severe neurological disability. On the $40^{\text {th }}$ day of her admission, the patient was discharged with severe neurological disability.

\section{Discussion}

Theophylline poisoning generally occurs due to an acute high dose intake as well as chronic intake of the medication. Among the toxicity symptoms with a theophylline plasma concentration over $20 \mu \mathrm{g} / \mathrm{ml}$ are headache, palpitation, dizziness, nausea, hypotension and precordial pain. In addition, it is possible for focal and generalized seizures to occur without the presence of any toxicity symptoms. The theophylline elimination half-life is reported to be 13-26 hours in newborns, 3-4 hours in children and 10-15 hours in adults at normal dosages ${ }^{4}$.

In addition to theophylline's short therapeutic interval, a number of drugs, diet and habits such as alcohol and cigarette use also change the personal pharmacokinetic characteristics and can exacerbate the detrimental effects of theophylline. Therefore careful and attentive use is required for every age group ${ }^{4}$. Our patient developed dehydration for three reasons: vomiting, diuresis linked with theophylline and the diuretic effect of indapamide, which she had also taken. The latter also caused acute renal failure.

Extracorporeal treatment methods are recommended for patients who do not respond to supportive treatment in theophylline toxicity. Hemodialysis, hemoperfusion, continuous venovenous hemodiafiltration (CVVHDF), peritoneal dialysis, and plasma exchange can be used as extracorporeal treatment methods. These methods can be life-saving for toxicities such as theophylline, lithium, salicylate and alcohol toxic 
poisoning, which can lead to mortal results ${ }^{5}$. Intensivists can provide various modalities of continous renal replacement therapies (CRRTs), especially CVVHDF, in the intensive care unit in the management of extracellular fluid volume overload and renal failure. The role of CRRT for the removal of xenobiotics (drugs and toxins), however, is not well defined. Some patients, particularly those who are hemodynamically unstable, are not suitable for conventional hemodialysis, and may warrant a trial of CRRT. There are a handful of case reports on the use of CRRT in the management of theophylline toxicity ${ }^{6}$.

One prospective study compared poisoned patients treated with hemoperfusion $(n=17)$ to those treated with hemodialysis $(n=39)^{7}$. Both groups were comparable at baseline in regard to age, interval time from ingestion to presentation, admission and peak (theophylline), time to peak (theophylline), type of poisoning, symptoms at initiation of extracorporeal treatments (ECTR), incidence of vomiting, and interval time from presentation to ECTR. Although the reason for preference for either hemoperfusion or hemodialysis was not stated, there was no statistical difference in outcome: the rate of major toxicity during or after ECTR as well as mortality was comparable in both groups. However, there was significantly more procedure-related complications in the hemoperfusion group ( $18 \%$ vs. $0 \%, p=0.007)$. Other comparative studies did not evaluate ECTR as a factor associated with outcome, so they were only included in the analysis for patient-level data if the information was available ${ }^{8}$. Evidence suggests that theophylline is readily dialyzable and that enhancing elimination with hemodialysis or hemoperfusion is superior to multi-dose activated charcoal ${ }^{9}$.

The efficacy of CVVHD for removing some highly protein-bound xenobiotics may be enhanced by adding albumin to the dialysate. Albumin-enhanced dialysate has been reported in one case to treat a 6.5 -month-old with valproic acid toxicity and a carbamazepine overdose in a 10-year-old ${ }^{10,11}$. Theophylline is approximately $50-60 \%$ protein bound and under normal conditions metabolized by the p450 enzyme in the liver ${ }^{12}$. For these reasons, we did not add albumin to the dialysate fluid. To the best of our knowledge, the use of CVVHD has not been reported previously in children and adolescents for theophylline ingestion in any age group. The theophylline level of the patient under CVVHD decreased rapidly; her hemodynamics improved and kidney functions returned to normal. But the patient was discharged with neurological sequelae due to the severe and prolonged hypotensive condition prior to the application and remained for a long time status epilepticus.

In conclusion, although theophylline poisoning is rarely seen in children, it should be noted that it can cause mortality and morbidity. In cases of theophylline poisoning, treatment should be started in the early stages, the patient's hemodynamics should be supported and extracorporal treatment methods should be used in severe poisoning cases. Patients with hemodynamic instability from theophylline intoxication must be considered for CVVHD in PICUs.

\section{REFERENCES}

1. Derby LE, Jick SS, Langlois JC, Johnson EL, Jick H. Hospital admission for xanthine toxicity. Pharmacotherapy1990; 10: 112-114.

2. Shannon M. Predictors of major toxicity after theophylline overdose. Ann Intern Med 1993; 119: 1161-1167.

3. Hall KW, Dobson KE, Dalton JG, Ghignone MC, Penner SB. Metabolic abnormalities associated with intentional theophilline overdose. Ann Intern Med 1984; 101: 457-462.

4. Charehsaz M, Gürbay A, Karakılıç ME, Şahin G. Theophylline: Adverse effects, poisoning and treatment approaches. J Clin Anal Med 2011; 2: 157-163.

5. Açıkalın A, Gülen M, Kösenli Ö, Topal M. Teofilin zehirlenmesi: Hemodiyaliz mi? Hemoperfüzyon mu? Acil Tip Olgu Sunumları Dergisi 2011; 2:39-41.

6. Goodman JW, Goldfarb DS. The role of continuous renal replacement therapy in the treatment of poisoning. Semin Dial 2006; 19: 402-407.

7. Shannon MW. Comparative efficacy of hemodialysis and hemoperfusion in severe theophylline intoxication. Acad Emerg Med 1997; 4: 674-678.

8. Sessler CN. Theophylline toxicity: clinical features of 116 consecutive cases. Am J Med 1990; 88: 567 -576.

9. GhannoumM, WiegandTJ, LiuKD, etal.Extracorporeal treatment for theophyllinepoisoning: systematic review and recommendations from the EXTRIP workgroup. Clin Toxicol 2015; 53: 215-229.

10. Chadha V, Pattaragarn A, Lowry J, Garg U, Blowey DL. Enhancement of valproic acid removal during CVVHD by the addition of albumin to dialysate (Abst). Pediatr Nephrol 2002; 17: C149.

11. Askenazi DJ, Goldstein SL, Chang IF, Elenberg E, Feig DI. Management of a severe carbamazepine overdose using albumin-enhanced continuous venovenous hemodialysis. Pediatrics 2004; 113: 406-409.

12. De Pont AC. Extracorporeal treatment of intoxications. Curr Opin Crit Care 2007; 13: 668-673. 